\title{
Avaliação da Degradação Térmica e Fotooxidativa do ABS para Fins de Reciclagem
}

\author{
Elisabete M. S. Sanchez \\ Faculdade de Química, CEATEC, PUC - Campinas \\ Maria Isabel Felisberti, Carlos A. R. Costa, Fernando Galembeck \\ Instituto de Química, UNICAMP
}

Resumo: Este trabalho tem como objetivo avaliar a degradação térmica e fotooxidativa do terpolímero poli(acrilonitrilabutadieno-estireno), ABS, utilizado em componentes internos de automóveis. Corpos-de-prova de ABS moldados por injeção foram submetidos ao envelhecimento térmico, segundo a norma ASTM D794, e ao envelhecimento fotooxidativo segundo as normas ASTM G24 e G53. As amostras envelhecidas foram submetidas às análises dinâmico-mecânica e microscópicas por microscopia de força atômica, no modo não contato. Os resultados mostraram que as transições, tanto da fase vítrea quanto da fase elastomérica na superfície do ABS, são afetadas pela degradação. As áreas dos picos das curvas de módulo de perda em função da temperatura relativos às transições vítreas do ABS foram correlacionadas ao alongamento na ruptura, em função do tempo e tipo de envelhecimento. As propriedades mecânicas são influenciadas de forma mais acentuada pela extensão da degradação da matriz. O método de envelhecimento ASTM G24 mostrou-se mais agressivo que o G53, seja para a fase BR ou para a fase SAN. As imagens microscópicas mostraram que os diferentes envelhecimentos provocaram diferentes variações na rugosidade das superfícies. Amostras fotooxidadas, com perda de alongamento maior que 50\%, foram reprocessadas e mostraram uma recuperação superior a $90 \%$ nessa propriedade.

Palavras-chave: $A B S$, degradação, propriedades mecânicas, reciclagem.

\section{Evaluation of Thermal and Photo-oxidative ABS Degradation with Recycling Purposes}

Abstract: The aim of this work is the evaluation of thermal and photo-oxidative degradation of the terpolymer acrylonitrile-butadiene-styrene, ABS, used in internal automotive components. Injection molded specimens were aged according to ASTM D794, ASTM G24 and ASTM G53 standards. The aged test specimens were studied by means of dynamic mechanical analysis and non-contact atomic force microscopy. The results revealed that the transitions of the glass and rubber phases were affected by degradation. The area under the linear loss modulus-temperature curves was related to tensile properties as a function of the aging time and standard test method. The degradation of the matrix had a higher influence on the mechanical properties. Both PB and SAN phases were more affected when the ASTM G24 standard test method was used. Microscopy images showed that distinct ageing methods cause different changes on the surface roughness. The results showed that an ABS that had lost $50 \%$ of rupture elongation has this property almost regenerated (90\%) after being reprocessed.

Keywords: ABS, degradation, mechanical properties, recycling.

\section{Introdução}

A degradação de polímeros inclui todas as mudanças na estrutura química e nas propriedades físicas resultantes de tensões mecânicas externas. Geralmente, a degradação deteriora as propriedades mecânicas dos materiais poliméricos. Dependendo da estrutura, um polímero é vulnerável a efeitos do ambiente, como o calor, o oxigênio e as suas formas ativas, a umidade, as emissões de poluentes atmosféricos, $\operatorname{como} \mathrm{NO}_{x}$ e a radiação ${ }^{[1]}$.

Os copolímeros e blendas contendo elastômeros têm grande importância comercial devido à sua alta resistência ao impacto, entre outras propriedades. $\mathrm{O}$
ABS é composto por monômeros cujos homopolímeros têm natureza elastomérica e termoplástica, e exibe excelente tenacidade e boa estabilidade dimensional. Essas resinas encontram ampla aplicação sobretudo na confecção de eletrodomésticos, telefones, na indústria automobilística e mais recentemente na confecção de cartões telefônicos. Portanto, existe uma tendência cada vez maior de descarte de produtos de ABS no ambiente, muitas vezes em estágio avançado de degradação.

O componente elastomérico, geralmente o polibutadieno (BR) ou um copolímero de butadieno, forma uma fase dispersa no termoplástico, que é um copolímero de estireno e acrilonitrila (SAN). O componente BR tem sido considerado o principal responsável pela de-

Autor para correspondência: Elisabete M. S. Sanchez, PUC - Campinas, CEATEC, Faculdade de Química, Rodovia D. Pedro I, km 136, Campinas, SP. E-mail: elisabete.sanchez@puc-campinas.edu.br 
gradação do $\mathrm{ABS}^{[1-5]}$. A fotooxidação do $\mathrm{ABS}$ leva à reticulação do componente elastomérico, e deteriora as propriedades elásticas nessa fase ${ }^{[5]}$.

A degradação térmica e fotooxidativa afeta de forma pronunciada as propriedades macroscópicas do ABS, tais como a cor e as propriedades mecânicas ${ }^{[6]}$. A transição vítrea das fases elastomérica e termoplástica também é afetada. A temperatura de transição vítrea, $T_{g}$, é determinada principalmente pela estrutura molecular das unidades repetitivas de um polímero. É na região da transição vítrea que se concentra o maior potencial de absorção e dissipação de energia mecânica. Nos primeiros estágios da degradação a maioria das unidades repetitivas da cadeia polimérica não sofre alteração, mas existem fatores secundários que também podem alterar a transição, como a massa molar, a extensão de reticulação e a concentração de plastificantes. A cisão de cadeias tem como conseqüência o aumento do volume livre, acarretando o abaixamento da $\mathrm{T}_{\mathrm{g}}$; o aumento da densidade de reticulação aumenta a rigidez do polímero e conseqüentemente a $\mathrm{T}_{\mathrm{g}}$ e, uma diminuição na concentração de plastificantes por volatilização, pode aumentar a $\mathrm{T}_{\mathrm{g}}$. Todos esses efeitos variam ainda em relação à distância do material analisado em relação à superfície, uma vez que a maioria dos processos degradativos se inicia na superfície. Além disso, os mecanismos de degradação também são influenciados pelo tempo e pela forma de envelhecimento.

Wyzgoski $^{[7]}$ avaliou o envelhecimento térmico do ABS entre $40{ }^{\circ} \mathrm{C}$ e $90{ }^{\circ} \mathrm{C}$, em atmosfera de nitrogênio, e correlacionou a perda de alongamento em função da temperatura e do tempo de envelhecimento com a relaxação secundária da fase termoplástica, concluindo que a perda da propriedade é consequiência do envelhecimento físico. Não foram observadas mudanças aparentes de morfologia.

Adeniyi e Kolawole ${ }^{[2]}$ estudaram a degradação termooxidativa $\left(100{ }^{\circ} \mathrm{C}\right)$ e fotooxidativa $(\lambda=254 \mathrm{~nm} \mathrm{e}$ $30{ }^{\circ} \mathrm{C}$ ) do ABS por FTIR. Os resultados sugeriram que a degradação do BR é controlada pela reatividade dos isômeros 1,2-vinila, cis e trans-1,4-butadieno. Os três isômeros do BR são degradados por mecanismos semelhantes, no entanto, o 1,2-vinila apresenta maior facilidade de formar radicais, devido ao hidrogênio lábil localizado em um carbono terciário. A iniciação envolve a abstração do hidrogênio para produzir um radical alquila, que se combina com o oxigênio para produzir um radical peróxido de alquila, que a seguir abstrai um hidrogênio da cadeia para produzir um hidroperóxido de alquila. A subseqüente degradação é propagada pela decomposição dos hidroperóxidos.

Adeniyi e Kolawole ${ }^{[2]}$ verificaram também que a concentração de ligações $\mathrm{C}=\mathrm{C}$ no $\mathrm{ABS}$ diminui com o tempo, sendo a diminuição mais pronunciada nas amostras submetidas à degradação térmica do que fotoquímica.

Embora a degradação do ABS venha sendo bastante investigada, existem vários aspectos não explorados, tais como a relação entre a extensão da degradação e as propriedades macroscópicas e microscópicas. Os ensaios de degradação são normalmente conduzidos em condições muito diferentes das condições normais de uso. Na maioria das vezes são utilizados filmes, enquanto que nos automóveis, por exemplo, utiliza-se peças moldadas por injeção.

Neste trabalho verificou-se que para peças moldadas a degradação/reticulação da fase elastomérica não é o principal fator responsável pela deterioração das propriedades mecânicas em peças moldadas por injeção. Por outro lado, a degradação da superfície da matriz tem um papel fundamental nas alterações observadas. Isto possibilita o reprocessamento do ABS, obtendo-se uma alta recuperação das propriedades mecânicas.

\section{Experimental}

O ABS utilizado foi o Cycolac GMP 5600 (GE Plastics South America Ltda.), de alto fluxo e resistência ao impacto, não pigmentado e moldado por injeção na forma de corpos de prova de tração (ASTM D638).

Os métodos de envelhecimento foram: 1) térmico em estufa marca Fanem, a $80 \pm 3{ }^{\circ} \mathrm{C}$ (ASTM D794); 2) fotoquímico segundo a norma ASTM G53, utilizando radiação UV-B filtrada por vidro, no equipamento C-UV Comexim, a $50 \pm 5^{\circ} \mathrm{C}$, e 3) térmico e fotoquímico em uma caixa preta sem ventilação, recoberta por vidro, construída segundo a norma ASTM G24. Os dados de radiação foram obtidos através do CEPAGRI-UNICAMP, mensalmente. A temperatura no interior da caixa e no ambiente de teste foi medida diariamente entre 12 e $13 \mathrm{~h}$.

No primeiro método avaliou-se o efeito da temperatura, no caso $80^{\circ} \mathrm{C}$, que representa uma temperatura crítica para um automóvel fechado e exposto ao sol. No segundo método foram analisados os efeitos causados pela exposição à radiação UV-B, filtrada por vidro, cujo espectro de emissão é mais próximo do solar e menos drástico que a radiação UV-B sem filtro, com temperatura na faixa de $50{ }^{\circ} \mathrm{C}$. E, finalmente, no terceiro método as amostras foram expostas à radiação solar, sob vidro, em uma caixa preta, que simula o interior de um carro fechado. A extensão da degradação oxidativa foi determinada por FTIR. As propriedades macroscópicas tais como propriedades mecânicas de tração, impacto, índice de fluidez, cor, também foram determinadas ${ }^{[6]}$.

Neste trabalho é dada ênfase à avaliação microestrutural do ABS em função do tempo e da forma de envelhecimento. Para isso utilizou-se a técnica de análise dinâmico-mecânica e análise da topografia por microscopia de força atômica no modo não contato (Modelo Discoverer TopoMetrix). O comportamento dinâmico-mecânico foi correlacionado com a propriedade mecânica de alongamento na ruptura.

Antes de iniciar o envelhecimento, todas as amostras foram submetidas a tratamento térmico a $90{ }^{\circ} \mathrm{C}$ por $30 \mathrm{~min}$ em atmosfera de argônio para uniformizar a sua história térmica e minimizar as possíveis tensões produzidas na moldagem por injeção.

Amostras submetidas às diferentes formas de envelhecimento foram retiradas em intervalos definidos de tempo e avaliadas por análise dinâmico-mecânica.

A análise dinâmico-mecânica foi realizada em cortes dos corpos de prova de impacto, no sentido longitudinal, de for- 
ma a avaliar prioritariamente a superfície exposta à radiação ou ao calor. Amostras com espessura média de $0,6 \mathrm{~mm}$ foram obtidas na máquina de cortes ISOMET 2000, Boehler, com carga de $600 \mathrm{~g}$ e velocidade rotação de $2000 \mathrm{rpm}$, com disco de diamante. Os experimentos foram conduzidos na faixa de temperatura de -150 e $200{ }^{\circ} \mathrm{C}$, sob a taxa de aquecimento de $2{ }^{\circ} \mathrm{C} / \mathrm{min}$, a freqüência de $1 \mathrm{~Hz}$ e amplitude de 0,2 mm, no equipamento DMA983 - TA Instruments. As curvas de módulo de perda em função da temperatura, E" $\times \mathrm{T}$, foram normalizadas para corrigir as possíveis flutuações no sinal do equipamento e nas dimensões das amostras.

Para o reprocessamento foi utilizado, para cada método fotooxidativo, o material envelhecido com aproximadamente $50 \%$ de perda de alongamento na ruptura (a partir de 240 h para o método ASTM G24 e a partir de 780 h para o método ASTM G53), em comparação a amostras não envelhecidas. Os corpos de prova, submetidos ao envelhecimento em apenas um lado, foram moídos em um moinho de facas e novos corpos de prova foram moldados por injeção em uma injetora Arburg $221 \mathrm{~K}$ na seqüência de temperaturas de $100,195,220,235$ e $240{ }^{\circ} \mathrm{C}$ nas cinco zonas de aquecimento. A temperatura do molde foi de $50{ }^{\circ} \mathrm{C}$. Os ensaios mecânicos de tração foram realizados segundo a norma ASTM D638, com célula de carga de $500 \mathrm{~N}$, à velocidade de 10 mm/min, no equipamento EMIC DL 2000. Esses ensaios reproduziram as condições utilizadas para avaliar o material envelhecido ${ }^{[6]}$.

\section{Resultados e Discussão}

A degradação de materiais poliméricos expostos ao ambiente tende a ocorrer devido a uma ação combinada de radiação ultravioleta, de calor e do oxigênio atmosférico. Os defeitos são iniciados na superfície do material e se propagam para o interior deste, como se o objeto exposto fosse constituído por camadas superpostas. As propriedades macroscópicas refletem o material como um todo, com as contribuições individuais das fases que o formam. Desta forma, as propriedades macroscópicas refletem os efeitos da degradação e dos diferentes métodos de envelhecimento ${ }^{[6]}$.

Na Figura 1 são apresentadas as curvas de módulo de perda em função da temperatura para amostras submetidas à degradação térmica, segundo a norma ASTM D794. A amostra não envelhecida apresenta três relaxações. A primeira, estreita e bem definida, com máximo a $-85^{\circ} \mathrm{C}$ e com um ombro a $-75{ }^{\circ} \mathrm{C}$, corresponde à transição vítrea da fase elastomérica, o BR. A segunda, uma relaxação larga entre $-55^{\circ} \mathrm{C}$ e $95{ }^{\circ} \mathrm{C}$, é atribuída a relaxações secundárias, $\beta$, da fase SAN, e uma terceira relaxação mais estreita com máximo em $108{ }^{\circ} \mathrm{C}$, correspondente à transição vítrea da fase $\mathrm{SAN}^{[7]}$. A presença de um ombro na fase $\mathrm{BR}$ caracteriza dois ambientes distintos nessa fase.

As mudanças ocorridas com o envelhecimento podem ser observadas em todas as curvas. $\mathrm{O}$ pico relativo à fase elastomérica dispersa se desloca entre $-85^{\circ} \mathrm{C}$ e $-79^{\circ} \mathrm{C}$ dependendo do tempo de exposição, e tem sua intensidade diminuída. A 2544 h o pico da fase elastomérica se sobrepõe à relaxação secundária da fase $\mathrm{SAN}$, resultando em uma transição larga entre $-100{ }^{\circ} \mathrm{C}$ e $75^{\circ} \mathrm{C}$.

A Figura 2 mostra as curvas de módulo de perda em função da temperatura para as amostras envelhecidas fotoquimicamente pelo método ASTM G53. A amostra submetida à radiação e temperatura de aproximadamente $50{ }^{\circ} \mathrm{C}$, por $72 \mathrm{~h}$, revela um aumento da intensidade de todas as rela-

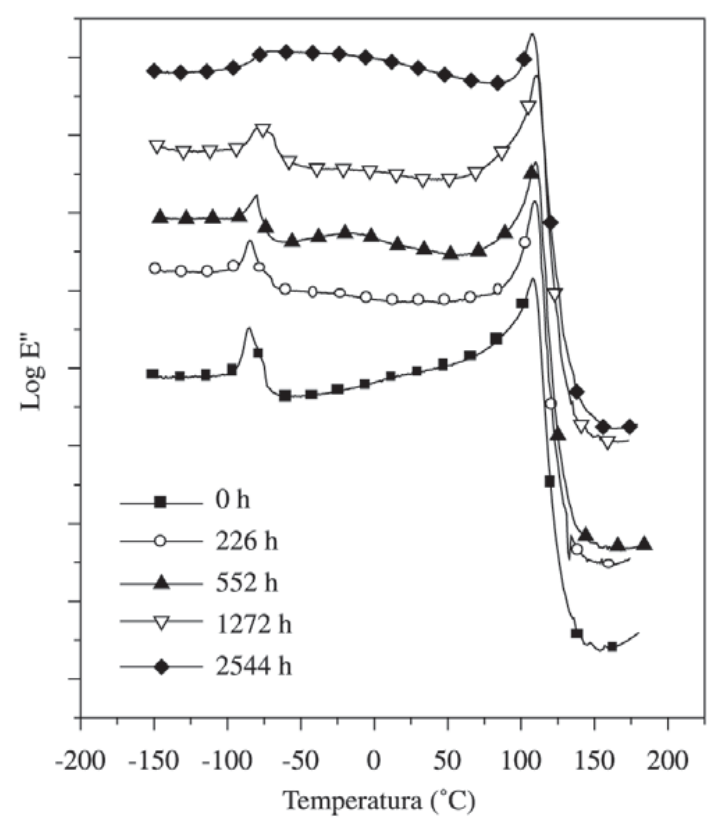

Figura 1. Curvas de $\log \mathrm{E} " \times \mathrm{T}$ para o ABS envelhecido pelo método ASTM D794.

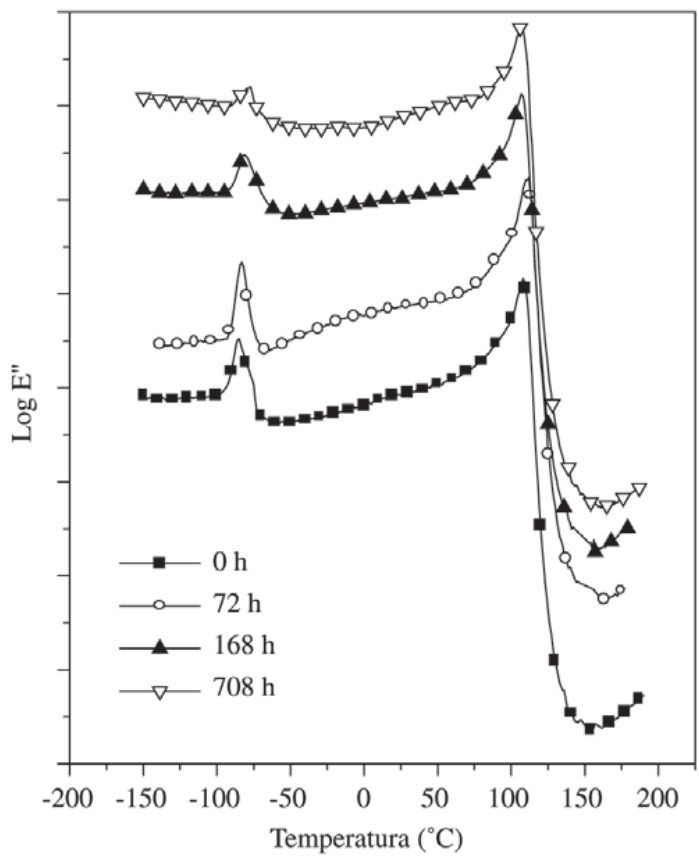

Figura 2. Curvas de $\log \mathrm{E} " \times \mathrm{T}$ para o ABS envelhecido pelo método ASTM G53. 
xações na faixa de temperatura analisada. É possível, que com poucas horas de envelhecimento a amostra tenha sofrido um relaxamento de tensões, promovendo maior liberdade de movimentação das cadeias em todos os segmentos. E, este efeito de relaxamento tenha sobrepujado os efeitos iniciais da degradação.

Com o aumento do tempo de envelhecimento observase a tendência de diminuição da intensidade do pico relativo à transição vítrea da fase elastomérica e também da relaxação secundária da fase SAN.

Na Tabela 1 são mostrados os valores médios para a temperatura e a radiação incidente para cada intervalo de envelhecimento a que as amostras foram submetidas no método ASTM G24.

Os resultados obtidos para as amostras envelhecidas pelo método ASTM G24 são mostrados na Figura 3. A relaxação secundária da fase SAN tende a ser suprimida e as intensidades dos picos relativos à transição vítrea das fases elastomérica e termoplástica tendem a diminuir com o aumento do tempo de envelhecimento.

Na Tabela 2 são mostradas as temperaturas de transição vítrea referentes às fases BR e SAN para os três métodos de envelhecimento em relação ao tempo. $\mathrm{O}$ aumento da $\mathrm{T}_{\mathrm{g}}$ nas duas fases é compatível com o aumento de rigidez verificado nos ensaios mecânicos ${ }^{[6]}$.

A área sob a curva de $\log$ E" em função da temperatura é proporcional à energia mecânica dissipada pelo sistema, que por sua vez é proporcional à concentração das espécies, grupos ou segmentos que sofrem relaxações nessa faixa de temperatura ${ }^{[8]}$. Essa área pode ser bastante afetada pela morfologia em sistemas poliméricos multicomponentes e também pela degradação.

Para comparar os efeitos do envelhecimento em cada método utilizado, foram calculadas as áreas dos picos sob as curvas $\log$ E" $\times$ T. Para tanto, utilizou-se uma linha de base traçada a partir das curvas de $\log \mathrm{E}$ " $\times \mathrm{T}$ a temperaturas abaixo e acima do pico de transição ${ }^{[8]}$. Para a relaxação da fase BR analisou-se a região de -150 a $-50{ }^{\circ} \mathrm{C}$ e para a fase $\mathrm{SAN}$ a região de -50 a $150{ }^{\circ} \mathrm{C}$.

Os resultados experimentais são apresentados na forma de razão entre as áreas, correspondentes à fase BR e SAN, das amostras envelhecidas pela área da amostra inicial (tempo 0).

Nas Figuras 4, 5 e 6 são mostradas as variações nas áreas relativas para as fases BR e SAN para os métodos ASTM D794, G53 e G24, respectivamente.

No método ASTM D794 a transição vítrea da fase SAN foi mais afetada que a fase BR. Portanto, o envelhecimento térmico afetou mais a matriz do que a fase elastomérica dispersa.

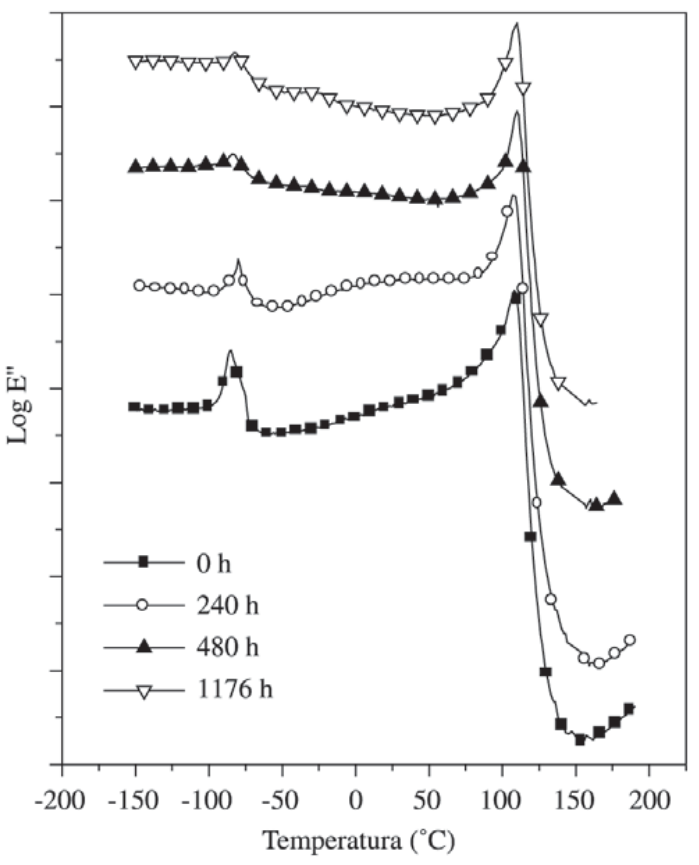

Figura 3. Curvas de $\log \mathrm{E} " \times \mathrm{T}$ para o ABS envelhecido pelo método ASTM G24.

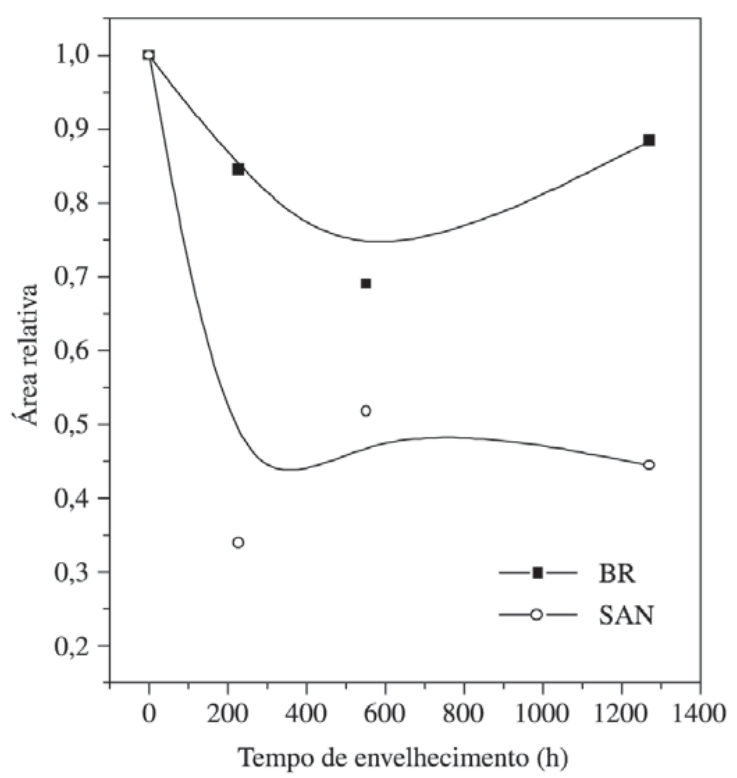

Figura 4. Variação nas áreas relativas dos picos correspondentes à transição vítrea da fase BR e da fase SAN de amostras envelhecidas segundo o método ASTM D794.

Tabela 1. Dados meteorológicos para o método ASTM G24.

\begin{tabular}{ccccc}
\hline $\begin{array}{c}\text { Tempo de } \\
\text { envelhecimento }(\mathbf{h})\end{array}$ & $\begin{array}{c}\text { Período } \\
\text { Ano } \mathbf{1 9 9 9}\end{array}$ & $\begin{array}{c}\text { Temperatura média } \\
\text { na caixa }\left({ }^{\circ} \mathbf{C}\right)\end{array}$ & $\begin{array}{c}\text { Temperatura média } \\
\text { ambiente }\left({ }^{\circ} \mathbf{C}\right)\end{array}$ & $\begin{array}{c}\text { Radiação incidente } \\
\text { média }\left(\mathbf{W} / \mathbf{m}^{2}\right)\end{array}$ \\
\hline 240 & $29 / 11$ a 09/12 & $47 \pm 7$ & $38 \pm 5$ & $230 \pm 7$ \\
480 & $29 / 11$ a $18 / 12$ & $48 \pm 7$ & $39 \pm 4$ & $230 \pm 7$ \\
1176 & $25 / 09$ a $13 / 11$ & $37 \pm 10$ & $29 \pm 5$ & $180 \pm 8$ \\
1860 & $25 / 09$ a 26/11 & $38 \pm 10$ & $30 \pm 5$ & $190 \pm 8$ \\
\hline
\end{tabular}


Tabela 2. Temperaturas de transição vítrea para o ABS submetido a três métodos de envelhecimento.

\begin{tabular}{|c|c|c|}
\hline $\begin{array}{l}\text { Tempo de } \\
\text { envelhecimento }(h)\end{array}$ & $\begin{array}{c}T_{g} \text { da fase BR } \\
\left({ }^{\circ} \mathrm{C}\right) \pm 1 \% \\
\end{array}$ & $\begin{array}{c}T_{g} \text { da fase SAN } \\
\left({ }^{\circ} \mathrm{C}\right) \pm 1 \%\end{array}$ \\
\hline \multirow[t]{2}{*}{0} & $-85,-75^{*}$ & 108 \\
\hline & ASTM D794 & \\
\hline 226 & -85 & 110 \\
\hline 552 & -80 & 110 \\
\hline \multirow[t]{2}{*}{1272} & -79 & 111 \\
\hline & ASTM G53 & \\
\hline 72 & -83 & 112 \\
\hline 168 & -81 & 107 \\
\hline \multirow[t]{2}{*}{708} & -77 & 107 \\
\hline & ASTM G24 & \\
\hline 240 & -80 & 107 \\
\hline 480 & -84 & 110 \\
\hline 1176 & -82 & 110 \\
\hline
\end{tabular}

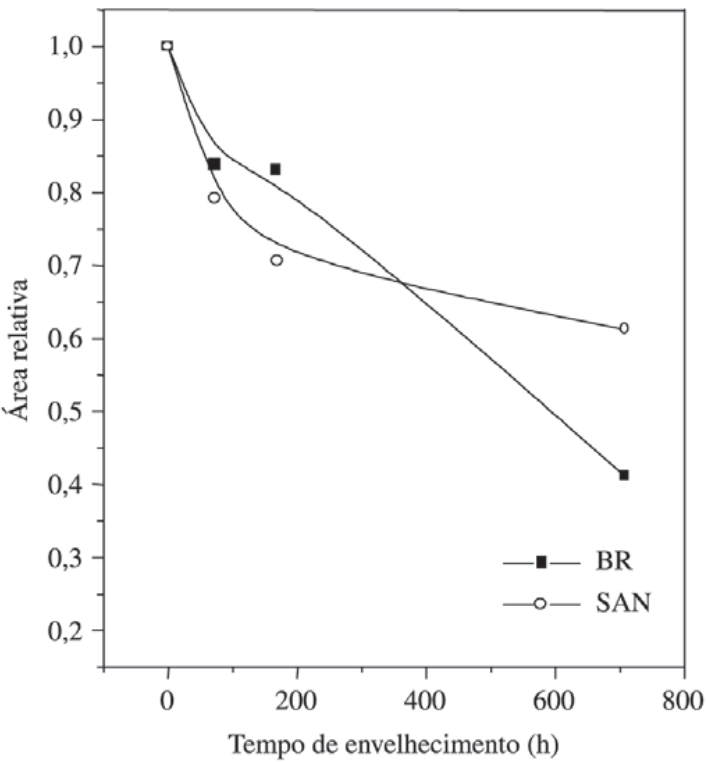

Figura 5. Variação nas áreas relativas dos picos correspondentes à transição vítrea da fase BR e da fase SAN de amostras envelhecidas segundo o método ASTM G53.

No método ASTM G53, ambas as fases foram afetadas, mas a partir de aproximadamente $300 \mathrm{~h}$ acentua-se a degradação da fase BR, que apresenta uma diminuição mais significativa na área.

No método ASTM G24 ambas a fases são afetadas sendo que o BR se mostrou mais sensível até 480 h e o SAN após esse tempo.

As alterações nas superfícies podem ser verificadas nas imagens topográficas obtidas por microscopia de força atômica. A Figura 7 compara a superfície do ABS não envelhecido e após o envelhecimento por $2544 \mathrm{~h}$ a $80^{\circ} \mathrm{C}$ (ASTM D794). Verifica-se que a superfície da amostra não envelhecida apresenta baixa rugosidade $(\mathrm{rms}=39 \mathrm{~nm})$. A amostra envelhecida apresenta uma superfície mais lisa $(\mathrm{rms}=18 \mathrm{~nm})$, o que é provavel-

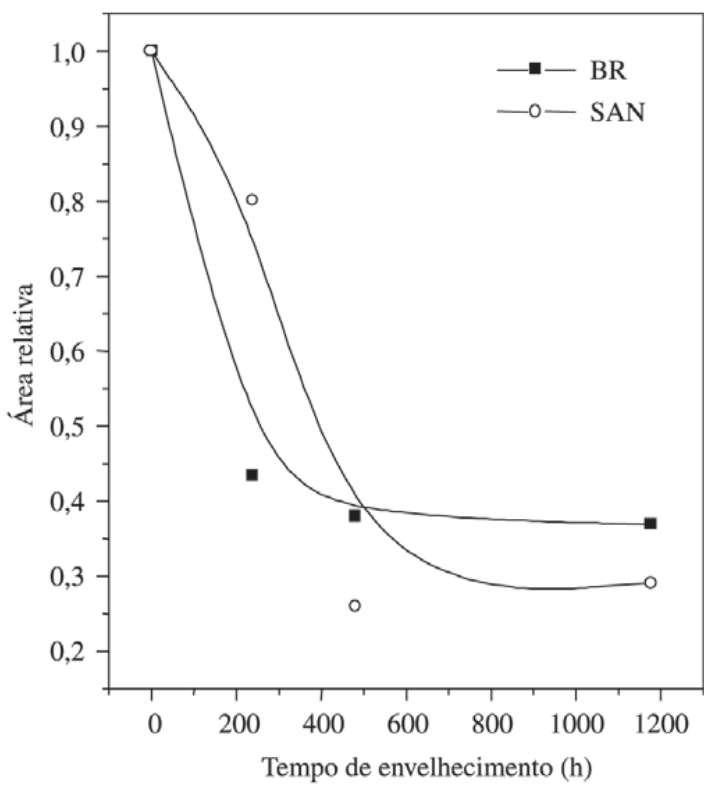

Figura 6. Variação nas áreas relativas dos picos correspondentes à transição vítrea da fase BR e da fase SAN de amostras envelhecidas segundo o método ASTM G24.

mente devido à ação da tensão superficial sobre a camada superficial, que se torna mais dinâmica devido à ocorrência de reações de degradação. Pode-se observar também partículas com diâmetro da ordem de $350 \mathrm{~nm}$.

A Figura 8 mostra as imagens da superfície do ABS envelhecido pelo método ASTM G24 por $50 \mathrm{~d}$ e por $2 \mathrm{a}$, respectivamente.

Podemos observar uma pequena diminuição de rms entre as Figuras 7 a e $8 \mathrm{a}(\mathrm{rms}=39$ e $35 \mathrm{~nm})$, o que indica que em um primeiro momento o processo de alisamento da superfície é predominante. $\mathrm{O}$ mesmo não é observado entre as Figuras $8 \mathrm{a}$ e $8 \mathrm{~b}(\mathrm{rms}=35$ e $58 \mathrm{~nm})$ submetidas apenas a envelhecimento fotooxidativo por 2 a, a temperaturas menores, onde outro processo degradativo passa a ser predominante, com aumento acentuado da rugosidade.

As Figuras 9 e 10 mostram, para os três métodos de envelhecimento, uma comparação entre o alongamento na ruptura relativo (razão entre o alongamento na ruptura para amostras envelhecidas e o alongamento na ruptura para a amostra não envelhecida) e as áreas relativas dos picos correspondentes às transições vítreas das fases BR e SAN, respectivamente.

Na Figura 9 é possível visualizar que a área relativa do pico correspondente à fase $\mathrm{BR}$ de amostras envelhecidas pelos métodos ASTM G53 e G24 mostra uma excelente correlação com o alongamento na ruptura relativo para todos os tempos de envelhecimento analisados, ou seja, ambos diminuem de forma similar com o aumento do tempo de envelhecimento. Entretanto, para amostras envelhecidas pelo método ASTM D794 esta correlação não é verificada na última determinação. Pode-se verificar ainda, que até cerca de 400 h de envelhecimento, ocorre uma diminuição mais drástica da área relativa do pico da transição vítrea da fase BR quando a amostra é envelhecida pelo método ASTM G24. Portanto o 


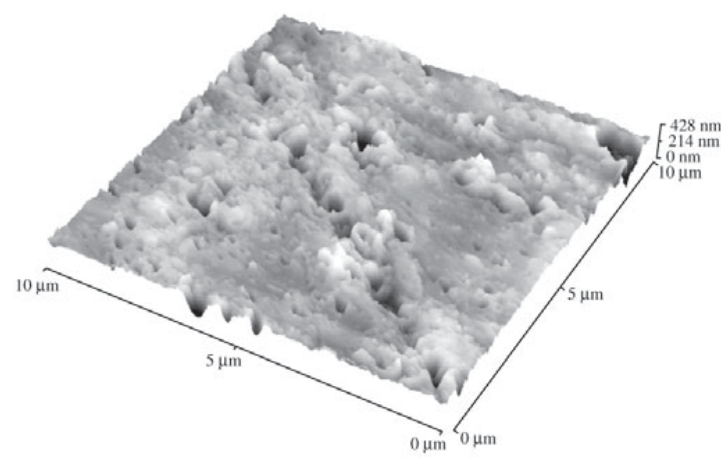

a)

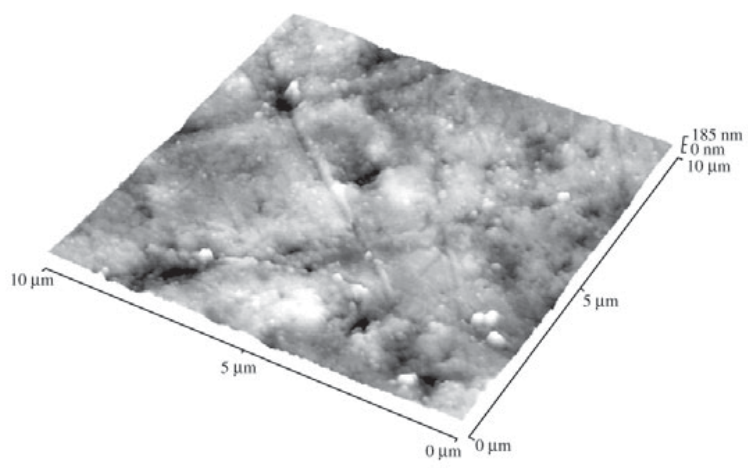

b)

Figura 7. Imagens topográficas por microscopia de força atômica de não contato para o $\mathrm{ABS}$ (a) não envelhecido e (b) envelhecido por $2544 \mathrm{~h}$ a $80^{\circ} \mathrm{C}$, pelo método ASTM D794.

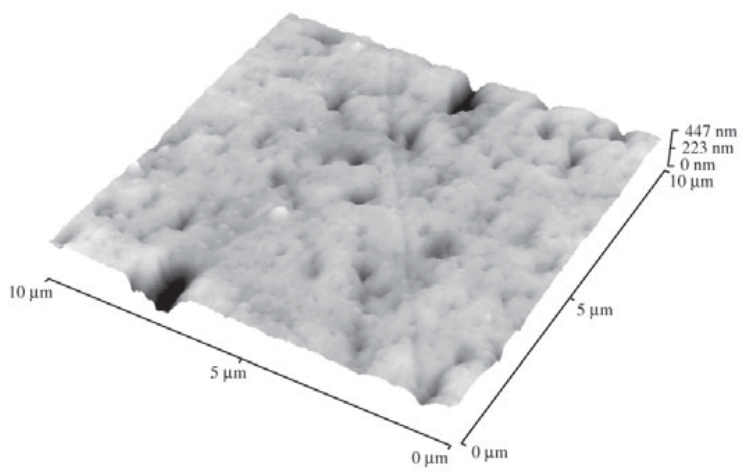

a)

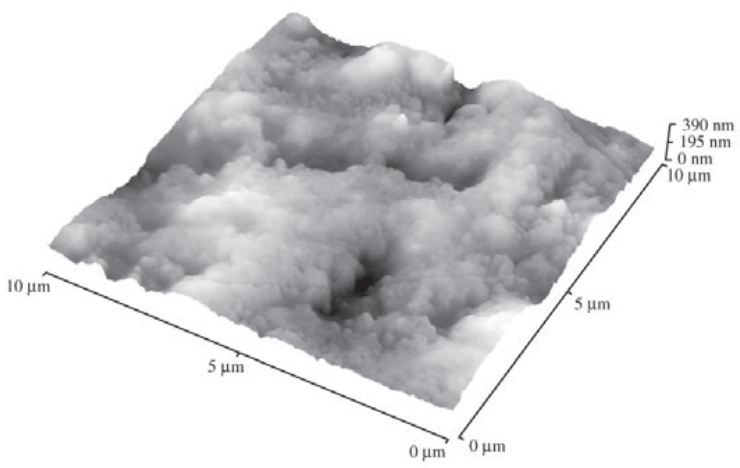

b)

Figura 8. Imagens topográficas por microscopia de força atômica de não contato para o ABS envelhecido pelo método ASTM G24 (a) 50 d e (b) 2 a.

método ASTM G24 mostra-se mais severo na etapa inicial da degradação da fase BR. A maior extensão da degradação verificada em amostras envelhecidas pelo método ASTM G24 pode ser explicada pelo fato das amostras terem sido sujeitas também à maior variação de temperatura ao longo do período. Acima de $400 \mathrm{~h}$ tanto a área relativa como o alongamento na ruptura relativo de amostras envelhecidas pelo método ASTM G24 não sofrem alterações significativas. Ao contrário, as amostras envelhecidas pelo método ASTM G53 e ASTM D794 continuam apresentando queda na área relativa para ambos os métodos e queda e aumento do alongamento relativo, respectivamente, com o aumento do tempo de envelhecimento.

Segundo Adeniyi ${ }^{[5]}$, a perda das propriedades elastoméricas pode ser associada num primeiro estágio com a perda de insaturação no BR. Sob condições mais severas há reticulação deste componente e cisão entre este e a matriz, sendo observado um aumento da área relativa após 1200 h de envelhecimento térmico pelo método ASTM D794.

A diminuição de área observada para a relaxação da fase elastomérica em amostras envelhecidas pelos métodos ASTM G53 e G24 pode ser atribuída a reticulação, que se dá em maior extensão nos métodos fotoquímicos. Portanto, a análise das áreas relativas para tempos de envelhecimento comparáveis indica uma forte dependência dos mecanismos de degradação da fase BR e dos produtos gerados.
Para a fase SAN observa-se tendências similares da área relativa ao pico da transição vítrea e do alongamento na ruptura relativo. Também para a fase SAN, o método de envelhecimento ASTM G24 mostrou-se mais severo no início da degradação.

Pela análise das áreas relativas dos picos correspondentes às transições vítreas do $\mathrm{ABS}$ concluiu-se que as fases $\mathrm{BR}$ e SAN são afetadas de forma similar para os métodos ASTM G53 e G24 (Figuras 5 e 6). Entretanto, para o método térmico ASTM D794, a fase SAN foi a mais afetada (Figura 4).

As curvas apresentadas nas Figuras 9 e 10 mostram que $\mathrm{a}$ área relativa para ambas as fases e o alongamento na ruptura relativo apresentam tendências similares com o aumento do tempo de envelhecimento para os métodos ASTM G53 e G24. Isto já não ocorre para as amostras envelhecidas pelo método ASTM D794, para as quais se observa uma melhor correlação entre o comportamento da área relativa do pico da transição vítrea da fase SAN e do alongamento na ruptura relativo para todo o intervalo de tempo de envelhecimento estudado. Este resultado sugere, que as perdas de propriedades mecânicas de tração de amostras envelhecidas pelo método ASTM D794 são mais afetadas pela extensão da degradação da matriz do que da fase elastomérica.

A Figura 11 compara os resultados obtidos nos ensaios mecânicos de tração (alongamento na ruptura) do ABS antes e após o reprocessamento (rep.) para os dois métodos de 


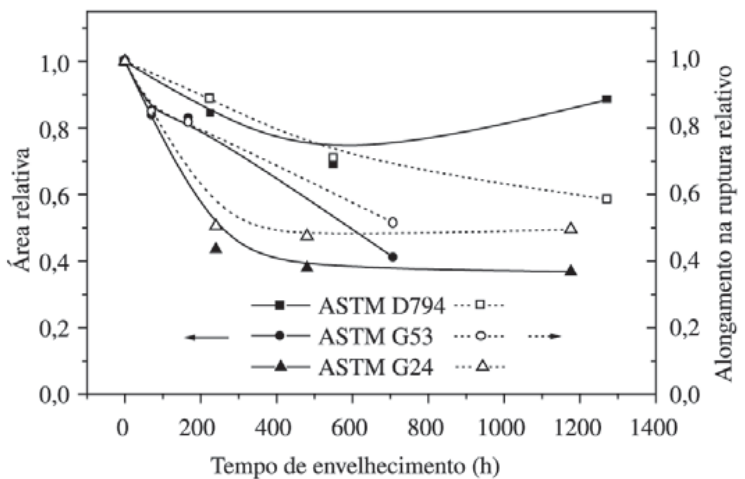

Figura 9. Área relativa do pico correspondente à transição vítrea da fase BR e alongamento na ruptura relativo ao valor inicial em função do tempo de envelhecimento para os três métodos.

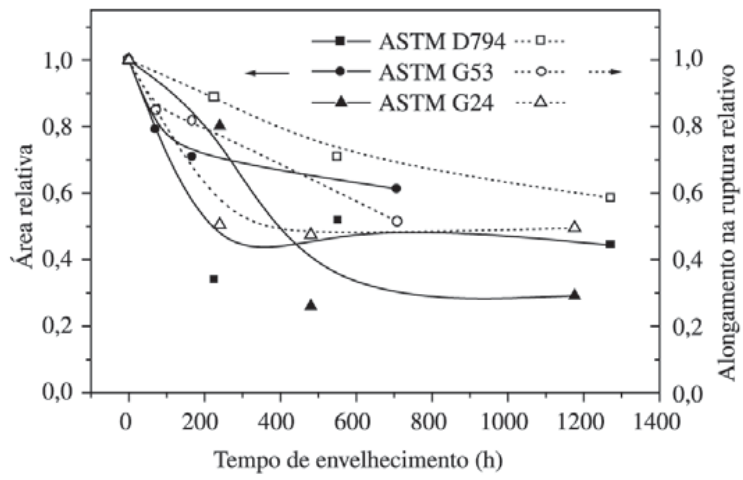

Figura 10. Área relativa do pico correspondente à transição vítrea da fase SAN e alongamento na ruptura relativo em função do tempo de envelhecimento para os três métodos.

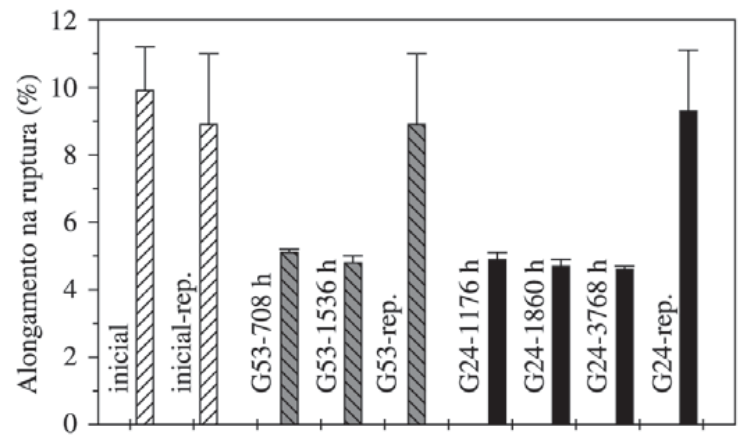

Figura 11. Alongamento na ruptura do ABS envelhecido e após reprocessamento (rep.) em comparação ao material não envelhecido.

envelhecimento fotoquímico.

As amostras envelhecidas pelo método ASTM G53 que mostraram perda superior a $50 \%$ de alongamento na ruptura, depois de moídas e reprocessadas apresentaram $90 \%$ de recuperação desta propriedade, e as envelhecidas pelo método ASTM G24 apresentaram 94\%. Porém essas amostras apresentaram um alto índice de amarelecimento, mostrando a necessidade de adição de colorantes ou pigmentos para se obter materiais reciclados com bom aspecto.

\section{Conclusões}

A comparação entre os resultados de ensaios mecânicos de tração e os resultados de análise dinâmico-mecânica, realizados com cortes de espessura de $0,6 \mathrm{~mm}$ dos corpos de prova envelhecidos, mostra claramente que as propriedades macroscópicas são governadas pelas propriedades da camada superficial degradada. Ambas as fases do ABS são afetadas pela degradação, sendo que no envelhecimento térmico (ASTM D794) a matriz foi mais afetada que a fase elastomérica. No método ASTM G53 ambas as fases são afetadas e o BR é mais afetado para tempos maiores de envelhecimento. Para o método ASTM G24, que combina calor e radiação, a fase BR é inicialmente mais afetada e para tempos maiores a degradação da matriz torna-se mais significativa.

A correlação encontrada entre a diminuição de área de picos relativos às transições vítreas do $\mathrm{ABS}$ e a diminuição do alongamento na ruptura mostra que a degradação de ambas as fases contribuem para a deterioração das propriedades do ABS, embora na literatura, a degradação do ABS tenha sido atribuída predominantemente à fase $\mathrm{BR}$.

A reciclagem do $\mathrm{ABS}$ exposto à intempérie é possível, mesmo para amostras que já perderam suas propriedades de alongamento na ruptura, pois o material degradado na superfície é diluído em seu interior, recuperando o alongamento máximo em mais de $90 \%$.

As alterações das superfícies foram verificadas por imagens topográficas de microscopia de força atômica de não contato, que mostraram que os diferentes envelhecimentos provocaram diferentes variações na rugosidade.

\section{Agradecimentos}

À FAPESP e à GE Plastics South America Ltda. pelo ABS.

\section{Referências Bibliográficas}

1. Pospisil, J.; Horák, Z.; Krulis, Z.; Nespurek, S.; Kuroda, S. Polym. Deg. Stab., 65, p. 405, 1999.

2. Adeniyi, J.B.; Kolawole, E.G. Eur. Polym. J., 20, p. 43, 1984.

3. Jouan, X.; Gardette, J.L. Polym. Deg. Stab., 36, p. 91, 1991.

4. Gardette, J.L.; Mailhot, B.; Lemaire, J. Polym. Deg. Stab., 48, p. 457, 1995.

5. Adeniyi, J.B. Eur. Polym. J. - 20, p. 291, 1984.

6. Sanchez, E.M.S.; Ferreira, M.M.C.; Felisberti, M.I. Polímeros: Ciência e Tecnologia, Out/Dez, p. 116, 1999.

7. Wyzgoski, M.G. J. Appl. Polym. Sci., 25, p.1443, 1980.

8. Fay, J.J.; Thomas, D.A.; Sperling, L.H. J. Appl. Polym. Sci., p.1617, 1991.

Recebido: 04/12/2002

Aprovado: 30/04/2003 